\title{
ADAMS_Based Research on Vibration Isolation Performance of Powertrain Mounting System
}

\author{
Xiaozheng $\mathrm{Li}^{1, \mathrm{a}}$, Ke Chen ${ }^{1, \mathrm{~b}}$ \\ ${ }^{1}$ School of automobile and traffic, Shenyang Ligong University, Shenyang, 110159, China \\ aemail: 657603172@qq.com, bemail: chen_ke@163.com
}

Keywords: Powertrain system model; Mounting system; Vibration Isolation

\begin{abstract}
The vibrations of vehicle engine powertrain is one of the main vibrations sources of whole vehicle. Severe vibrations can not only cause the vehicle structure fatigue and damage, but also affect the durability and comfort of the vehicle. What's more, it can influence interior personnel's physical health. So isolating the vehicle frame/body from the vibration of powertrain is becoming more and more important. Based on the 6 degrees of freedom model of powertrain, this article will build 12 degrees of freedom vehicle model to analyze the rubber mounting system's vibration isolation.
\end{abstract}

\section{Introduction}

With the vehicles' developing in high speed and lightweight, vibration noise problem increasingly prominent. People's requirement of vibration and noise is stricter. While we all know the vehicle comfort, ride comfort, engine vibration and vibration isolation can't leave vibration analysis. Vehicle engine powertrain has two main vibration sources of inspiration. One is from the road, another is from the operation of the engine and transmission system. In this paper, 12 degrees of freedom vehicle dynamics simulation model is built using ADAMS software, and each mounting's vibration situation is analyzed ${ }^{[1,2]}$.

\section{The establishment of the powertrain model and the vehicle model}

Engine CYQD32T powertrain mounting system simulation model and vehicle mounting system simulation model are set up as shown in the figure 1 and figure 2.

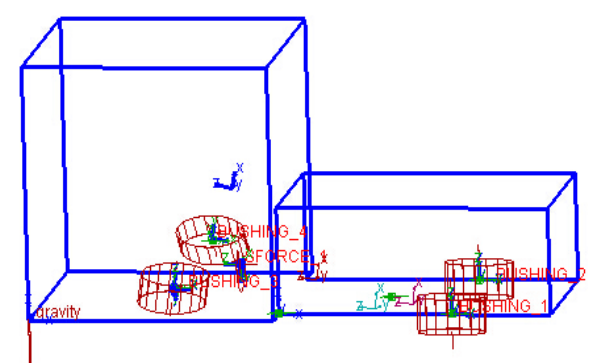

Figure 1 Powertrain mounting system simulation model

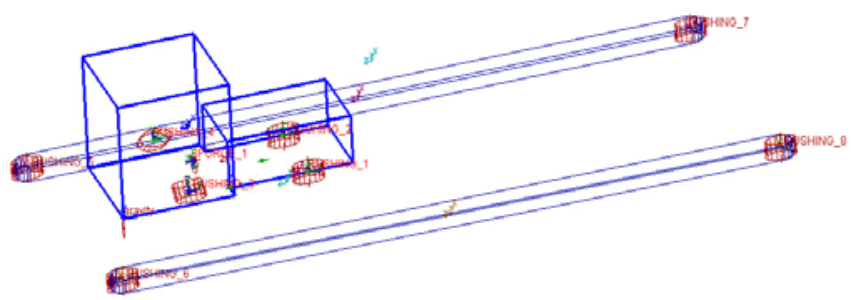

Figure 2 Vehicle mounting system simulation model

This article is mainly to research the working condition when the engine speed at $1500 \mathrm{r} / \mathrm{min}$. Moment of inertia and rubber mounting components characteristics of the engine and vehicle parameters are shown in table 1 and table $2^{[3,4]}$.

Table 1 Moment of inertia parameters

\begin{tabular}{llllllll}
\hline & $\begin{array}{c}M \\
(\mathrm{~kg})\end{array}$ & $\begin{array}{c}\mathrm{I}_{\mathrm{X}} \\
\left(\mathrm{kgm}^{2}\right)\end{array}$ & $\begin{array}{c}\mathrm{I}_{\mathrm{Y}} \\
\left(\mathrm{kgm}^{2}\right)\end{array}$ & $\begin{array}{c}\mathrm{I}_{\mathrm{Z}} \\
\left(\mathrm{kgm}^{2}\right)\end{array}$ & $\begin{array}{c}\mathrm{I}_{\mathrm{XY}} \\
\left(\mathrm{kgm}^{2}\right)\end{array}$ & $\begin{array}{c}\mathrm{I}_{\mathrm{YZ}} \\
\left(\mathrm{kgm}^{2}\right)\end{array}$ & $\begin{array}{c}\mathrm{I}_{\mathrm{XZ}} \\
\left(\mathrm{kgm}^{2}\right)\end{array}$ \\
\hline $\begin{array}{l}\text { Engine } \\
\begin{array}{l}\text { Vehicle } \\
\text { body }\end{array}\end{array}$ & 327.2 & 17.84 & 28 & 22.6 & 0.44 & 1.43 & -2.09 \\
\hline
\end{tabular}


Table 2 Mounting elements characteristic parameters

\begin{tabular}{cccccc}
\hline & $\begin{array}{c}\mathbf{K}_{\mathrm{x}} \\
(\mathrm{N} / \mathrm{mm})\end{array}$ & $\begin{array}{c}\mathbf{K}_{\mathbf{y}} \\
(\mathrm{N} / \mathrm{mm})\end{array}$ & $\begin{array}{c}\mathbf{K}_{\mathrm{z}} \\
(\mathrm{N} / \mathrm{mm})\end{array}$ & $\begin{array}{c}\text { Damp } \\
(\mathrm{Ns} / \mathrm{mm})\end{array}$ & $\begin{array}{c}\text { Installation angle } \\
(\text { degree })\end{array}$ \\
\hline $\begin{array}{c}\text { Engine front } \\
\text { mounting }\end{array}$ & 119 & 752.6 & 532 & 0.08 & 50 \\
$\begin{array}{c}\text { Engine rear } \\
\text { mounting }\end{array}$ & 282 & 52.1 & 114 & 0.08 & 0 \\
$\begin{array}{c}\text { Frame front } \\
\text { mounting }\end{array}$ & 21740 & 21740 & 217.4 & 1.897 & 0 \\
$\begin{array}{c}\text { Frame rear } \\
\text { mounting }\end{array}$ & 22350 & 22350 & 223.5 & 2.356 & 0 \\
\hline
\end{tabular}

\section{Vibration isolation analysis of the mounting system}

Pavement is usually described as a road roughness, and it's the main motivation passing to the vehicle in the process of driving. General accessing method is letting the vehicle along a road (skid pad and hyperbolic brick pavement) to measure vibration acceleration of mountings under the block along the $\mathrm{z}$ direction in the case of not starting the vehicle engine. And then we can convert it into power spectral density (PSD). In this article, we use the given spline curve spline1 (as shown in figure 3) to react powertrain excitation energy of acceleration power spectrum causing by the road roughness.

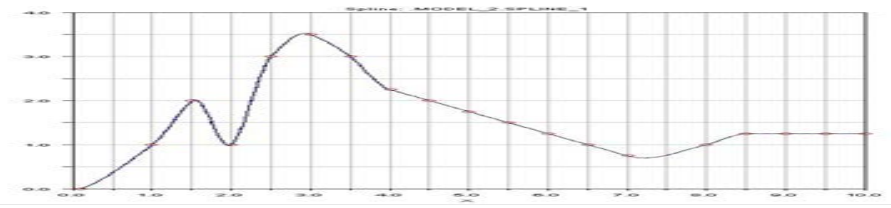

Figure 3 Spline1-road roughness of powertrain excitation energy of acceleration power spectrum

We have to simplify the force and torque to the engine of the powertrain mass center and add the expressions to the model. So the natural frequency of the engine can be calculated ${ }^{[5]}$.

Mounting system's natural frequency and modal can be obtained by the type:

$$
\begin{aligned}
& \left|K-\omega^{2} M\right|=0 \\
& \left\{K-\omega_{i}^{2} M\right\} \psi_{i}=0
\end{aligned}
$$

In the type: $\mathrm{K}$ is the stiffness matrix of mounting system; $\mathrm{M}$ is mass matrix

Mounting system's six order natural frequency and corresponding vibration model can be achieved by formula (1) and (2). When the mounting system vibrates by the natural frequency and corresponding vibration model, we can know the decoupling rate of energy as follow:

$$
\begin{array}{r}
E(n, i)=\frac{\frac{1}{2} \omega_{i}^{2} \varphi_{n i}}{\frac{1}{2} \omega_{i}^{2} \vec{\varphi}_{i}^{T} M \vec{\varphi}_{i}} \sum_{i=1}^{6} m_{n l} \varphi_{l i} \\
=\frac{\varphi_{n i}}{\vec{\varphi}_{i}^{T} M \vec{\varphi}_{i}} \sum_{i=1}^{6} m_{n l} \varphi_{l i}
\end{array}
$$

In the type: $\varphi_{l i}$ belongs to $\varphi_{i} ; m_{n l}$ belongs to $\mathrm{M}$

By looking for literature, we can find the required parameters. Then we put the parameters to the corresponding formula. Through calculation and analysis, we could get the mounting model natural frequency and energy distribution (decoupling) mounting model. They are showed in the table 3 and table $4^{[6]}$.

Table 3 Mounting model natural frequency

\begin{tabular}{ccccccc}
\hline $\begin{array}{c}\text { The main vibration } \\
\text { direction }\end{array}$ & $\mathrm{X}$ & $\mathrm{Y}$ & $\mathrm{Z}$ & $\mathrm{Rxx}$ & $\mathrm{Ryy}$ & $\mathrm{Rzz}$ \\
\hline $\begin{array}{c}\text { Natural } \\
\text { frequency }(\mathrm{Hz})\end{array}$ & 6.42 & 7.25 & 11.99 & 14.17 & 13.61 & 10.14 \\
\hline
\end{tabular}


Table 4 Energy distribution (decoupling) mounting model

\begin{tabular}{|c|c|c|c|c|c|c|}
\hline $\begin{array}{l}\text { The main energy } \\
\text { distribution direction }\end{array}$ & X & $\mathrm{Y}$ & Z & $\mathrm{Rxx}$ & Ryy & Rzz \\
\hline $\begin{array}{c}\text { Energy } \\
\text { distribution (\%) }\end{array}$ & 84.99 & 61.93 & 72.94 & 61.34 & 76.55 & 63.89 \\
\hline (20000. & 38. 0 & $\begin{array}{r}39.0 \\
\operatorname{Time}(s)\end{array}$ & & & & $y_{42.0}$ \\
\hline 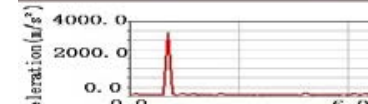 & & & & & & \\
\hline
\end{tabular}

Figure 4 Acceleration PSD of the upper portion of front-left mounting cushion on Z-axis direction $(\mathrm{n}=1500 \mathrm{r} / \mathrm{min})$

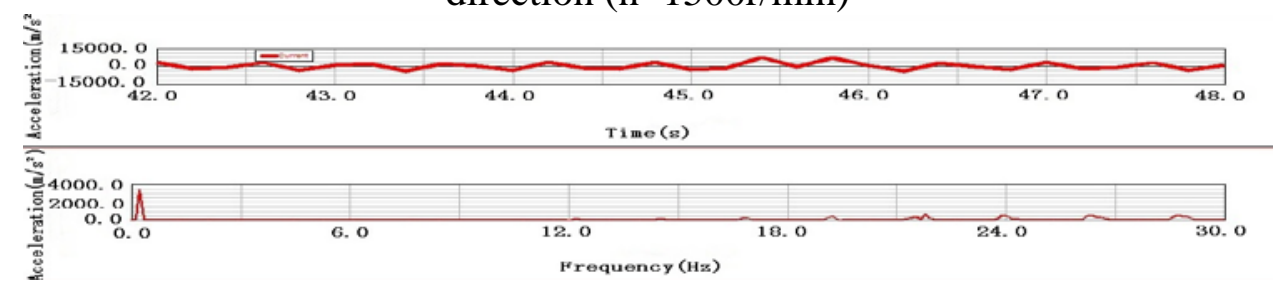

Figure 5 Acceleration PSD of the lower portion of front-left mounting cushion on Z-axis direction ( $\mathrm{n}=1500 \mathrm{r} / \mathrm{min})$

From figure 4 to figure 5, through observing the acceleration curves of the upper and the lower, we could find that the front-left mounting cushion absorbed lots of vibrations.

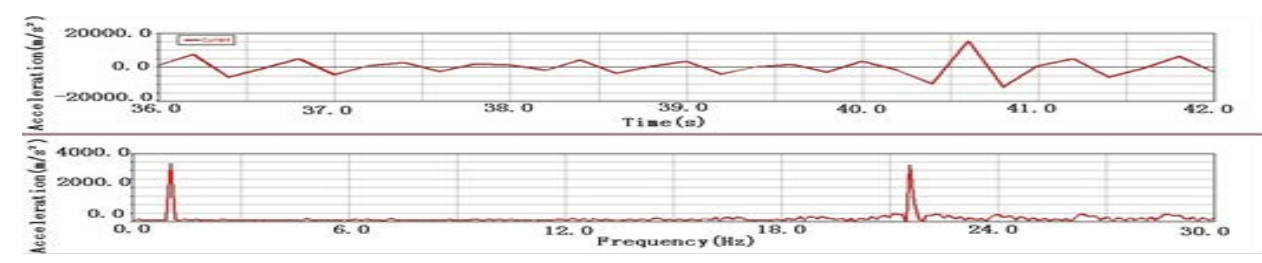

Figure 6 Acceleration PSD of the upper portion of front-right mounting cushion on Z-axis

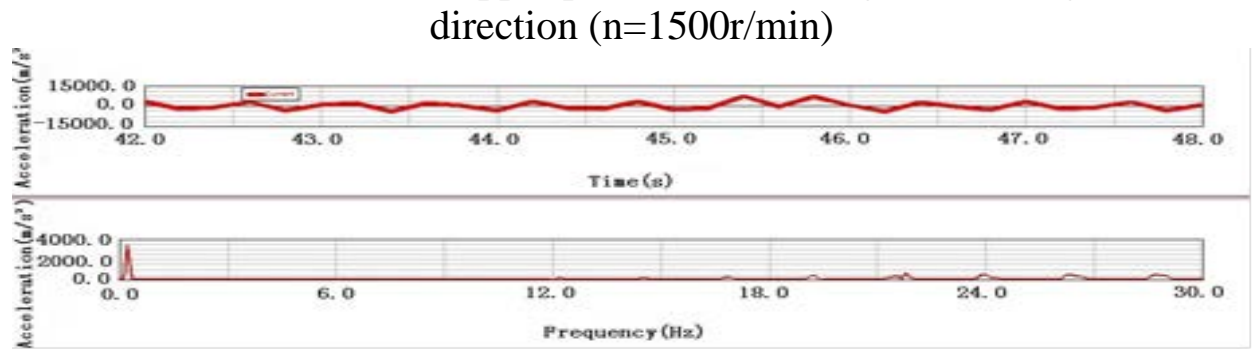

Figure 7 Acceleration PSD of the lower portion of front-right mounting cushion on Z-axis direction ( $\mathrm{n}=1500 \mathrm{r} / \mathrm{min})$

From figure 6 to figure 7, through observing the acceleration curves of the upper and the lower, we could find that the front-right mounting cushion absorbed lots of vibrations.

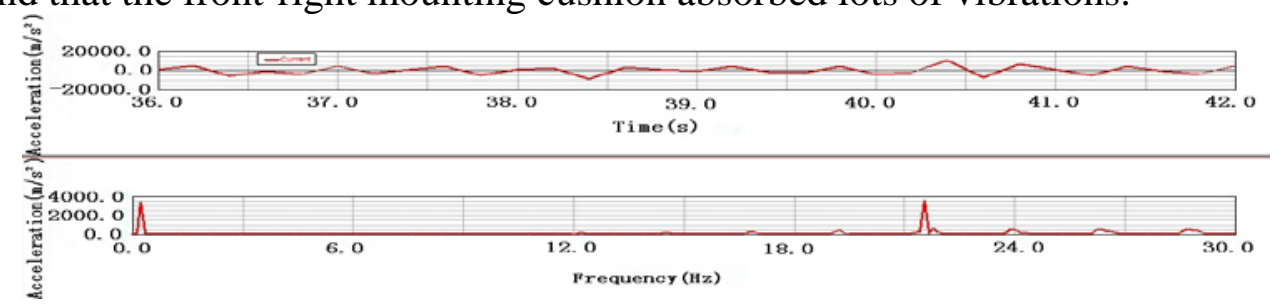

Figure 8 Acceleration PSD of the upper portion of left cushion of rear mounting on Z-axis direction $(\mathrm{n}=1500 \mathrm{r} / \mathrm{min})$ 


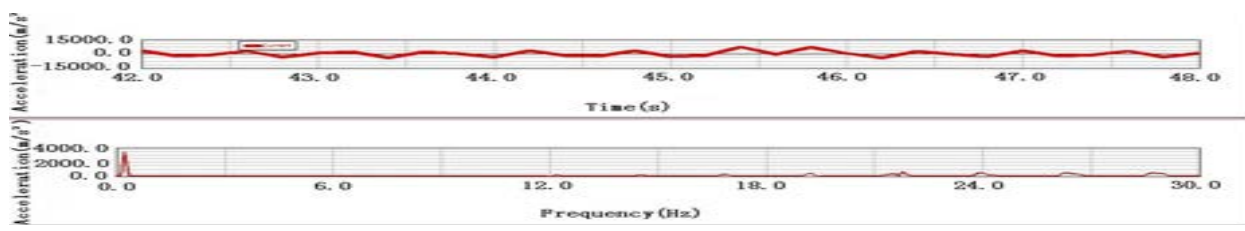

Figure 9 Acceleration PSD of the lower portion of left cushion of rear mounting on Z-axis direction ( $\mathrm{n}=1500 \mathrm{r} / \mathrm{min})$

From figure 8 to figure 9, through observing the acceleration curves of the upper and the lower, we could find that the rear-left mounting cushion absorbed lots of vibrations.

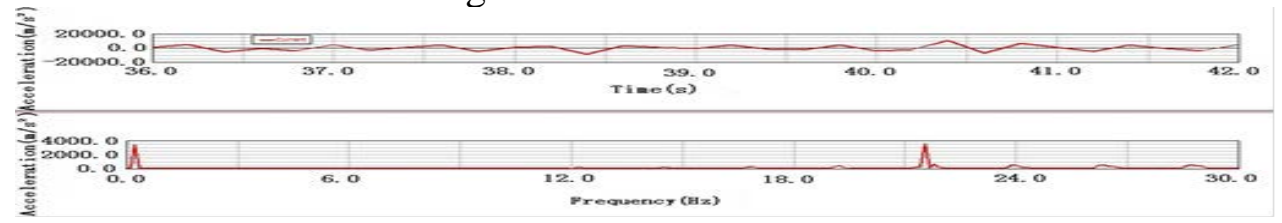

Figure 10 Acceleration PSD of the upper portion of right cushion of rear mounting on Z-axis direction ( $\mathrm{n}=1500 \mathrm{r} / \mathrm{min})$

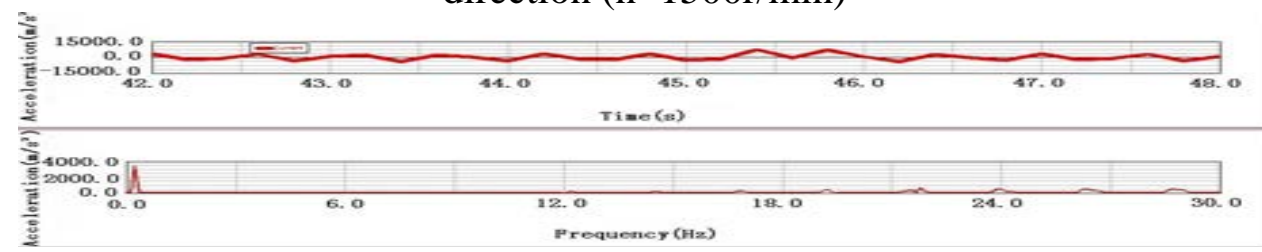

Figure 11 Acceleration PSD of the lower portion of right cushion of rear mounting on Z-axis direction ( $\mathrm{n}=1500 \mathrm{r} / \mathrm{min})$

From figure 10 to figure 11, through observing the acceleration curves of the upper and the lower, we could find that the rear-right mounting cushion absorbed lots of vibrations.

\section{Conclusion}

From figure 4 to 11, there are the acceleration power spectrum density curves of the upper and the lower mounting cushions, reflecting the size of the acceleration power spectrum at different frequencies. We can know the second-order inertia force vibration frequency is $23.2 \mathrm{~Hz}$ from the acceleration power spectrum density curve. The vibration frequency in the mounting soft mat can be displayed especially in the former mounting's two cushions, but no performance at the bottom of the mounting soft mat. It shows that the second-order inertia on the engine vibration frequency in the frame and vehicle body has not been passed. On the contrary, they are absorbed by the mounting soft mat. This shows that mounting system does have the effect of the vibration isolation.

\section{References}

[1] John Brett. Optimization of Engine Mounting Systems to Minimize Vehicle Vibration. SAE Transactions Journal of Passenger Cars, 1993, 102: 1822-1829.

[2] Chung-Ha Suh, Clifford G. Smith. Dynamic Simulation of Engine Mounting Systems. SAE Transactions Journal of Passenger Cars, 1997, 106: 2778-2789.

[3] Fan Rang-lin, Lv Zheng-hua. Evaluation Approaches of Vibration-Mode Uncoupling for Multi-DOF Rigid-Body with Elastic Mounting System [J].Engineering Mechanics, 2006, 23(7): 13-18.

[4] Xu Yi, Wu Zhang-wei. Analysis and Optimization for Powertrain Mounting System Based on ADAMS [J]. Agricultural Equipment and Vehicle Engineering, 2013, 51(4): 53-57.

[5] Chen Ke, Lv Pin. Simulation Method for Vibration Isolation Performance of Vehicle Powertrain Mounting System [J]. China Mechanical Engineering, 2014, 25(20): 2830-2834.

[6] Li Zheng, Ji Jin-liang, Yang He-zhou, et al. Parameters Design of Vehicle Powertrain Mounts Based on Energy Decoupling[J]. Auto Mobile Science and Technology, 2011, 39(04): 25-27. 